\title{
Critical Organization of Knowledge in Mass Media Information Systems
}

\author{
Antonio García Gutiérrez* and Daniel Martínez-Ávila** \\ *Faculty of Communication, Seville University, C/Américo Vespucio s/n, \\ 41092 Seville, Spain, >algarcia@us.es> \\ **School of Information Studies, University of Wisconsin-Milwaukee, \\ Northwest Quad Building B 2025 E Newport St., Milwaukee, WI 53211 USA \\ $<$ avilad@uwm.edu >
}

\begin{abstract}
Antonio García Gutiérrez holds a Ph.D. in information sciences from Complutense University of Madrid and is a professor at the School of Communication in Seville University. He has acted as an information systems consultant for international organizations such as UNESCO, World Tourism Organization and as an evaluator of scientific projects for the Fifth Framework Programme of the European Union. He has written more than fifteen books that address the problems of knowledge organization and its construction from post-epistemological stances linked to objects related to cultural studies and the postcolonial approach, such as the memory, the experience, the identity and the culture.
\end{abstract}

Daniel Martínez-Ávila holds a Ph.D. from Universidad Carlos III de Madrid, Spain. He is a member of the Information Organization Research Group - FAPOI at São Paulo State University (UNESP), Marilia, Brazil. Currently, he is an adjunct instructor at the School of Information Studies, University of Wisconsin-Milwaukee. His research interests include the application of post-structural and critical theories to knowledge organization.

Antonio García Gutiérrez and Daniel Martínez-Ávila. Critical Organization of Knowledge in Mass Media Information Systems. Knowledge Organization. 41(3), 205-216. 60 references.

\begin{abstract}
This paper studies knowledge organization (KO) in media archives, focusing on the presence of subjectivity in the core tasks of mass media knowledge organizers (MKOS) dealing with press, radio and TV records, such as classification, representation, and any other process related to content analysis and organization in news information systems. Far from rejecting subjectivity and ideological bias in these operations - since they coparticipate in the media construction of reality - the authors consider MKOS to be genuine ideological and cultural mediators with the right and social responsibility to explicitly state the results of their "objectifiable" work (obtained through $\mathrm{KO}$ protocols and procedures determined by the media/company, classifications, thesauri, ontologies, etc.) and differentiate them from those of their political, ideological, cultural and, in sum, subjective stances. In order to achieve this, we propose the application of critical operators that should be followed by technical, collaborative and even technological actions geared to investing information systems with the capacity to consider those stances and allowing users to distinguish them. In short, it is the theoretical recognition of the subjective and biased presence of media knowledge organization operators in a job that is usually considered neutral, banal and even objective, and the initial development of tools for critical, self-critical, technical, and technological training keyed to its practical solution. This paper outlines the lines of work of a broader research study on the critical function of $\mathrm{KO}$ in the field of global media memory.
\end{abstract}

Received 22 August 2013; Revised 21 January 2014; Accepted 21 January 2014

Keywords: mass media knowledge organizers (MKOS), media, knowledge organization, operator, information, memory

\subsection{Introduction}

Mass media information systems and databases not only record every global event that has been reported by the
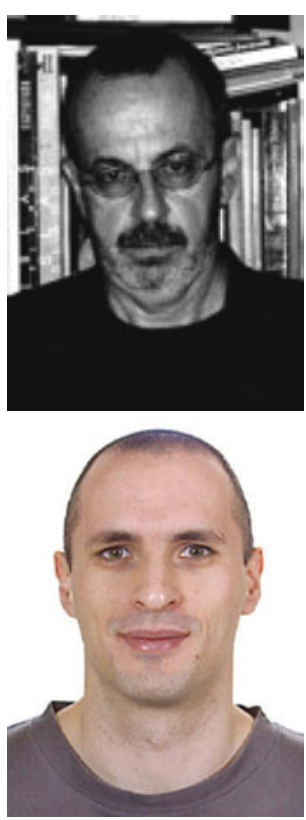
has been previously published but must also be considered "exomemory." As a result, these data repositories constitute one of the greatest narratives of everything that has happened in the world. It is, in fact, a narrative with the superstructure of the great metanarratives, in accordance with the postmodern terminology of Lyotard (1984), or even a "fourth bios," a "media bios" (that is, a "reality" that we all live and that is constructed by the media) as proposed by the Brazilian theorist Muniz Sodré (2002), from the perspective, discourse and agenda of the media, unparalleled by the information that states possess about their citizens or even by the exomemory that citizens possess about themselves.

In addition to the analogical exomemory that has existed since the first obituaries were filed in the dark "morgues" of American newspapers, or in the first British news libraries, described in the pioneering book by the BBC news information librarian Geoffrey Whatmore (1978), billions of current data in different visual and audiovisual formats are annually incorporated, filtered and channeled by the media to the digital exomemorythe compendium of media production on the Web. At a slower but inexorable "tempo," the digital production of news that directly and automatically becomes a part of the global digital exomemory occurs concurrently with the digitalization of old analogical TV, film, radio and printed press formats of all the countries, regions and cultures of the world, meaning that the current registered global memory will double in an ever shorter time, achieving an exponential growth that could lead to its saturation and collapse (cf. Huyssen 2000; Todorov 2000).

Not only the actors that ultimately produce iteditors, writers, reporters, and all types of technical and production staff-are involved in the process of building media memory. Although, since that first organized library was created by a newspaper, over a century ago, it is possible to talk about the responsibility of archivists, librarians, and documentalists in the construction of the narrative that the media weave about the present and the past, the role of these knowledge organizers (kos) has certainly become increasingly more important ever since the global media narrative first went digital. Computer experts and file system managers have taken center stage, and media knowledge organizers (MKOS) have to permanently redefine their technical functions, ethical and even political responsibilities, and the role that they play as anonymous specialists that operate in the core of the driver of global memory. Their work, always regarded as having more in common with shelves, files, and foldersbe they manual or digital — than with decisive ideological operations, such as selecting, discarding, classifying, ordering, analyzing, representing, normalizing, organizing, etc., information, acquires global importance in the digital world, not only to delimit and clarify their functions and responsibilities, implementing control mechanisms governing their operations, but also to establish them as guarantors of pluralism and freedom in putting into circulation the memory generated by the mass media and warning against the repercussions that their $\mathrm{KO}$ operations may have on the construction of local and global history.

To start with, a good example of this is the polarization that MKOS have to deal with in their daily work of selecting, organizing, and representing news: a story about a confrontation between the police and a group of demonstrators could be represented from the following ideological standpoints (and from multiple intermediate ones): law enforcement officers/police violence; rebellion/social rights; casualties/murder; or even urban street terrorism/civil self-defense. In his theory of text coproduction, Eco (1993) analyzes how the author of a text "voices" a series of ideas, while leaving others to be "voiced" by his or her "model reader." According to Eco, there is a model reader that is intuited by every author in his or her outputs for he or she "writes" (somehow linkable to the pathos of Aristotelian rhetoric). The media's "readers" (listeners, viewers, etc.) naturally form a part of this collaborative process, but what is the role of MKOS? Has mediation through $\mathrm{KO}$ operations a co-productive dimension? To what extent do mediators have the right and obligation to explain the biases in their productions, reproductions and co-productions? Traditionally, MKOS have not been "model readers" for authors of news stories, although, over recent decades, as with the scientific discourse, it has been observed that media authors (journalists, reporters, editors, etc.) have shown a need to participate in the organization of their own production; in the media, $\mathrm{KO}$ and kos are operations and operators more intuited- "modeled" in the sense of Eco-by producers, while at the same time there is growing empirical evidence of the role of $\mathrm{KO}$ mediators (co-producers) and MKOS in the construction of reality by the media, in accordance with the famous theory of Berger and Luckmann (1995), a reality of which the ways of organizing and preserving it form a part.

In the broadest sense of the word, MKOS are essentially readers of texts. Their core activity revolves around reading, but they do not read for themselves or for pleasure, and nor is it neutral reading, but reading for others; and be it cognitive or metacognitive, what is involved here is an ideologically-governed operation. The orientation of this reading in media $\mathrm{KO}$ processes might not be desirable, but it is inevitable and overt. Hence, this paper strives to detect and take advantage of it, rather than camouflaging or denying it. 


\subsection{Media knowledge organization in the context of KO studies}

While several studies have addressed significant problems in $\mathrm{KO}$ from different perspectives, talking about how to improve the practice of $\mathrm{KO}$ in different contexts and sharing a similar view to ours (e.g. Olson 1997a; 1997b; 1998 2000; 2001; 2002b; 2003; de la tierra 2008; Hogan 2010; Feinberg 2011a; 2011b; Fox and Reece 2013), relatively few studies in the field of $\mathrm{KO}$ have been devoted to the observation and reinstatement of the critical role of MKOS which should characterize practices in organization and mass media information systems. Furthermore, there has been mounting interest in organizing news and newspaper articles using automatic techniques such as text classification and indexing algorithms (e.g. Chen and Lin 2000; Evans and Klavans 2003; Casillas et al. 2003; Mamakis et al. 2011; Rocha and Cobo 2011), or, on occasion, those based on user-features, in a usercentered fashion, such as the automatic summarization and categorization of news derived from user choices (Banos et al. 2006), user modeling (Wongchokprasitti and Brusilovsky 2007), or user profiles (Bouras and Tsogkas 2010). However, as some authors have pointed out, automatic indexing and user-based retrieval systems such as Google's are not exempt from bias or subjectivity either (e.g. Segev 2009; Hjørland 2013). Concurrently, the ethical aspects of $\mathrm{KO}$ have also been revealed to be of great importance and concern to the scientific community in different areas and scenarios, as shown in the two editions of the conference on the ethics of information organization in 2008 and 2012 (see Olson 2009, and Martínez-Ávila et al. 2012 and others) and the work of authors such as Clare Beghtol (e.g. 2002; 2005), José Augusto Chaves Guimarães and Juan Carlos FernándezMolina (e.g. 2002; 2010), Hope Olson (e.g. 2002a; 2009), and Joe Tennis (e.g. 2012; 2013), among others. In addition, Sasaki et al. have also propounded the organization of news using a domain analytical approach (2012), while the Living Knowledge Project has studied the description of news and other information on the Web in relation to aspects such as diversity, opinion, bias and context, although focusing on techniques such as automatic classification and faceting and other aspects such as the public image of a company, PR campaigns and future predictions (Giunchiglia et al. 2009; Madalli and Prasad 2011).

Concerning subjectivity in $\mathrm{KO}$ in a broader sense, although some authors have worked with statistical methodology in combination with feature selection methods to extract subjectivity from documents (Sarvabhotla et al. 2011), the most common approach-leaving aside positivist views in which research on subjectivity was discarded for being considered unwelcome-has been the ethical one in which bias has even been discussed as a potentially positive feature (Feinberg 2007; Hjørland 2008), as well as forming a part of the legitimate plural construction of reality (García Gutiérrez 2002; 2007; 2011c). Considering this framework, since the construction of mass media memory would be one of the applied fields of $\mathrm{KO}$ involving the greatest socio-cultural risk and susceptibility, the article focuses on some of its strategic itineraries and dimensions. In addition, this paper shares with Bernd Frohmann (2008, 270) his appraisals on the discussion on subjectivity in relation to the ethical role of information and agency when, for instance, he points out that "a common feature of the subjectivity central to the information ethics of all four thinkers considered here is the moral, epistemological agent engaged in the process of understanding, deciphering, or 'decoding' the meaning of information brought to mind or consciousness, whether by other subjects or by the presence of the informing things of social and natural worlds," also adding that "Foucault, Deleuze, and Hacking show us a way of ethical thinking that illuminates a field of problems and issues in information ethics veiled from the perspective of a self-centered information ethics" (Frohmann 2008, 276).

Concerning reflexivity, this concept is mainly drawn from reflexive sociology. According to Bourdieu (2004, 4), reflexivity "is the image sent back to a knowing subject by other knowing subjects equipped with analytical tools which may have been provided to them by this knowing subject." A precursor of Bourdieu, and also a more radical stance, can be especially found on the reflexive sociology of Gouldner (1971, 481-489 passim): after exposing the biases of his opponents, the "hostile information," Alvin Gouldner decided to auto-reveal his own biases in an uncommon example of epistemological sincerity in the construction of scientific knowledge. In his way of explicitly stating his own consciousness, he reserved a bit of lucidity to confess that his own lucidity would never be full enough to avoid distortions in the process.

Restoring and reusing the achievements of this abandoned moral sociology, that would suppose a paradigm shift in the KO research and practices, for us, reflexivity is also a metacognitive process that enables the subject to analyze him/herself while analyzing, a process that enables to auto-evaluate in the moment of evaluating an object, text or practice. In this paper, we propose theoretical tools that will help the MKO to explicitly express her/his subjective position, in those aspects in which because of their highly sensitive political or ideological content it would be necessary to do so, while carrying out their tasks of analysis, classification and representation of media. It is obvious that it is not about hiding subjectivity but, on the contrary, opening a procedure to channeling it. 


\subsection{MKOS and the process of constructing recent memory}

All news stories, published or not, are filtered and organized to a lesser or greater extent by news professionals (librarians, archivists, documentalists), which in this work will be generally called MKOS. MKOS-namely, information professionals that process the journalistic discourse produced by any news actor with the aim of converting it into media exomemory-handle highly sensitive content from a social, political, cultural and ideological point of view, and their involvement in the process is neither aseptic nor devoid of prejudice, as it tends to appear at first glance thanks to positivist mythology. MKOS do a job that is not only logically and culturally keyed to the journalists working in the same company, but whose actions or omissions also have a global impact via the Web.

However much it can be related to machinery, digital applications and formats, their work is not objective, but, quite the contrary, their involvement in the construction of memory is highly subjective, active and self-serving, even when MKOS themselves refuse to admit it or sincerely believe that this is not so. Since they indisputably intervene in this construction using instruments (thesauri, ontologies, etc.) or $\mathrm{KO}$ operations, such as selection in which they choose or omit meanings, classification in which they label in one way or another, generalize or restrict by means of all sorts of rankings and associations, ordering in which they give priority to certain positions, and representation in which they decide on semantics and terminology, never devoid of ideology or bias, the aim of this paper is not to denounce the undeniable ideological mediation of MKOS or to demonstrate the non-existent subjectivity in their work. Rather, by acknowledging their subjective influence on the whole process, the idea is to make their operations more reliable by means of mechanisms of explanation and, therefore, of control, supervision and verification in each phase, reserving a place for the documentalist's own opinion or standpoint, otherwise indecipherable but decisive in media memory production. As Melanie Feinberg (2007), drawing on the idea of situated knowledges as expressed by Donna Haraway, stated: "If we cannot eliminate bias, then we should instead attempt to be more responsible about bias and explicitly decide on and defend the perspectives represented in our information systems." The inevitable subjectivity in the work of MKOS is therefore transformed into a positive and enriching resource in the process of construction and global circulation of that same memory-a subjectivity, then, at the service of transparency, pluralism, democracy and the profession's own ethical standards.

Regarding ideology, we agree with Joe Tennis (2013, 42) when he says that "ideology is a way of looking at things. It is the set of ideas that constitute one's goals, expectations, and actions." For the purpose of this work and unless otherwise expressly indicated, as the semantic precision of the concepts "opinion," "criticism" or "bias" are not particularly necessary, they will be used indistinctly or in accordance with the dominant subjective meaning in the general definitions found in Giunchiglia et al. (2009). MKOS are additional "mediators," "metamediators" in the complex process of journalistic discourse (post)production. Their job is not only to inform but also to opine, and, taking this to a higher level, to criticize.

In this paper, an effort will be made to doubly justify this activity as a right and to accept it as a reality that must be channeled, ethically and technically, so as to enhance its credibility. To a greater extent, if possible, than any other knowledge organizer, MKOS persistently express their opinion throughout the documentation-information process. Even if they are "obliged" by the editorial policy of the media company for which they work to channel and represent information in line with its ideology, these mediators still have plenty of leeway to introduce their subjectivity, cloaking, camouflaging and saturating the system in a subtle but effective fashion so as that records are retrieved along with a great amount of noise-i.e., the total number of retrieved documents contains a high proportion of irrelevant ones - or that records, even when they exist, cannot be retrieved at all. Rules, style books, controlled languages and other reference tools used for carrying out the documentation process to the media company's liking do not help to avoid the constant and subliminal presence of MKOS in all records.

Therefore, far from putting into place additional mechanisms for mitigating or stifling opinions, the intention of this paper is to liberate them, treat them as a right, include them in the general polyphonic process constituting recorded social memory, in which MKOS are privileged actors who have to be made aware of the real social responsibility of their discreet labor. So then, it is not only necessary to avoid "dissembling" or denying the presence of subjectivity in the results of $\mathrm{KO}$ operations, but also to place it under the protection of the basic civil rights enshrined in democratic constitutions and the International Bill of Human Rights.

Explicitly stating the opinion of MKOS in the organization and classification of the records of a media company would not then ensure the transparency of the majority of operations carried out on a consultable record, but embody the right of all MKOS to openly express their opinion and, more specifically, their critical standpoint with respect to the messages and content of the memory records that they put into circulation (becoming, in this sense and according to Eco, co-producers of the news stories of the journalists themselves). For one thing is evident: MKOS not only reproduce data but also co- 
produce and produce them. As a result, revealing this historically denied function would only contribute to the hygiene, diversity and pluralism of memory, in addition to introducing a minimum of scientific criteria in a process governed by uncontrollable parameters, such as intuition, experience, commonsense and personal "tendencies." The aforementioned problems ought to be addressed in a number of different ways: 1) in MKO training programmes; 2) the development of $\mathrm{KO}$ procedures and tools; and, 3) technological adaptations that facilitate the channeling of these transformations. In this paper, the authors intend to theoretically address the second initiative, focusing on operations of a discursive nature.

\subsection{The explicit subject}

With the advent of digital technology, the precarious and incipient research into media $\mathrm{KO}$ was reunited with the old mechanist utopia, taking a step back in the service of a dominant way of making science that it also applied itself: mediation and quantification, objectivity, separation between subjects and objects, technical jargon, systemization of the sciences, leadership of the "hard" disciplines, knowledge fragmentation and hyper-specialization. The digital boom revitalized the old objectivist ways of organizing journalistic knowledge, accompanied by a greater disregard, if possible, shown by MKOS for the discourses and ideologies governing their daily work.

In this context, the so-called "journalistic documentation"- - one of the applications with the richest cultural content and ideologically sensitive to LIS and KO issues, as well as being of considerable socio-historical importance in countries such as France and Spain, for instanceembraced technological progress, surrendering its discourse to the asepsis of technology. But no technology is neutral. Quite to the contrary, all technology is above all primordially a "techno-logic"-in other words, it contains the key elements of the culture that has invented it and the knowledge that it actually transmits. In this way, formats, fields, protocols or technical rules deriving from network computing constrict the natural rebelliousness of texts with rigid corsets shaped by their (techno)logic, and in doing so spread the illusion of the system and its operators' objectivity. After this turning-point, machines would interfere in the grammars of history. The algorithm subjugates the discourse in the production of truth in the scientific world, while political rhetoric dominates the society surrounding it. A product of the combinatorial randomness inherent to search engines, in which - true enough - the free choice of citizens in the conceptual flukes within the systems could be increasingly limited.

The case of written, visual and audiovisual journalistic records as the basis of a historical narrative has become perceptibly more dramatic with globalization. Nowadays, the most deeply-seated local history can be told by the strangest and remotest machine from the narrated individuals (heteronarrative). News from the Punjab reaches the Punjab filtered by American and European sources, media, mediations and servers. The digital network provides ever greater access, and even a visible participation, although practically irrelevant to historical narrative which is still woven from a metropolitan decentrality. This is one of the key elements of the postcolonial discourse. Machinist pseudo-neutrality is calling the shots in a gradually more muted global cultural polyphony.

Faced with this decentralization favoring the digitalwhich is indeed a stealthy, covert neo-centralization of a dominant culture, another "sweet totalitarianism" of consumption, as Marcuse would say-the social responsibility of MKOS as mediators and pre-narrators of recent history and memory is incalculable. Hence, far from dwelling on their pseudo-objectivism and promoting educational plans and activities keyed to creating the image of a professional that does not correspond to the reality of their profession, the "return of the subject" ought to be vindicated, also in our own field (Ibañez 1994): the reestablishment and acknowledgment of their subjectivity in the construction of global media memory, under certain conditions. For the time being, the existing systems only contain huge doses of deregulated subjectivity, chaotic and obscured, channeled by formal protocols with the appearance of transparency and objectivity.

The conditions for the presence of subjectivity in the management of media records must be governed by new methodologies that outline, paradoxically, three old and persistent epistemological principles that have usually shared even opposing paradigms in order to increase the reliability of the metacognitive processes at stake: 1) detecting and explaining stances; 2) supervising and reproducing phases and procedures; and 3) third-party checking.

Compliance with these conditions increases the process's reliability and versatility, with the following results and value added:

a) The resulting subjective dispersion of an analytic process is not only tolerable but also beneficial if it is controlled and identified as such, since this increases the level of transparency, pluralism, democracy and diversity in media KO.

b) The users of the system know, in a differentiated fashion, the objective and subjective reasons behind each analysis and representation, thus reducing the risk of manipulation.

c) Subjective positions can be corroborated with objective data obtained from the analysis so as to assess the judgment of the source and the mediators. 
d) The identification of a given $\mathrm{MKO}$ is conducive to the monitoring of his or her mediations in other records and even in major news stories, exceeding and enhancing this (his or her) habitually anonymous professional activity.

e) Any supervisor or MKO working in the scope of application and with the same materials and tools could also join in or check the track record of a $\mathrm{KO}$, understanding the steps taken, isolating the subjective positions, and achieving very similar analytic results in the objectifiable aspects of $\mathrm{KO}$ operations.

Some in-depth changes should be made in journalistic documentation systems and networks so the explicit statement of the subjectivities of those who operate on media memory records is something that is technically, professionally, economically, culturally and politically plausible. MKO associations, trade unions and even legislation would have to include the right and obligation of these mediators to proffer opinions and explicit criticism in the analyses that they conduct in a different place in the record than the rest of the supposedly objective analysis. In this way, users would also have more elements of judgment as regards the provenance and sources of the information and its degree of manipulation, as well as allowing them to differentiate between fact and opinion, and even heightening their awareness about the constant possibility that opinions might furtively be confused with hard facts. When stating this, however, the authors duck the issue of the interesting radical constructivist position (debunking constructivism) of authors such as Latour and Woolgar (1979), for instance, for whom explanations of facts are not only constructions but also the facts themselves.

Users have the right to know the stance of those that provide them with a record, all the more reason to stress the obligation and right of MKOS to make this plain. Furthermore, users have the right to know all the possible opinions about an issue; to have to all the existing value judgments, without restrictions or censorship. The use itself of a certain vocabulary, euphemisms and other rhetoric of power sidetrack the search. MKOS shoulder the democratic responsibility to reveal to users all the stances and manipulations related to an issue, including their own as mediators.

\subsection{Techno-ethical measures: the critical operator.}

The profound changes that must be made in the higher education programs should be accompanied by the development of an adequate space for its expression in all the phases of the process and tools involved in media $\mathrm{KO}$, in such a way so as to ensure that it is more than a mere desideratum. Hence, the possibility of introducing a "critical operator," complementary and transversal to associative and relational functions existing in one way or another in thesauri and ontologies, reflected in ad hoc fields of representation and reserved for the legitimate opinion of MKOS, is theoretically essayed below. The presence of representations that satisfy any MKO's ideological, political, sociocultural or identitary position must be guaranteed in the $\mathrm{KO}$ tools such as classifications and the aforementioned thesauri and ontologies. In these tools, that should also undergo transformations, the very structural location of the representations must also be guaranteed and governed by the principle of pluralism. The very structure of the representation language must be deeply democratic, that is open, because democracy does not allow limits. On the other hand, the operations and formats derived from the content analysis must provide spaces for the freedom of expression of the MKOS, that is, to satisfy their role as co-producers through critical content metadata, that must be clearly differentiated from those obtained as required reproducers of the author's position.

The critical operator is a development of the so-called techno-ethical operators thoroughly studied in García Gutiérrez (2004; 2007; 2011a; 2011b). At an obligatorily theoretical level in this phase of research, such operators open the way for and channel legitimate ethical and political stances that, like it or not, openly or stealthily flow through the discursive restructuring that kos introduce into the results of their operations. But, at a higher level of ontological and epistemological order, these operators contribute to the recording of $\mathrm{KO}$, as a scientific subject, in the set of so-called "emancipatory sciences," according to Jürgen Habermas (1971). Below, a brief look is taken at the theoretical properties of these previous operators in order to contextualize the identification of the specific functions and space reserved for the critical operator.

\subsection{Complex operator $\Lambda$}

The set of positions on an issue can be included in what has been called, in other works, "complex operator." The meaning of the adjective "complex," allocated to this operator, is inspired by Edgar Morin's theory of complexity (1996) and the decisive role that "opposites-complementaries" play in it for the complex understanding of reality. What is involved is an analytic operator of representation, transversal to other operators of thesauri and ontologies, and with possibility of being present in the fields of representation of media memory records, organizing the positions on an issue using the semantic range provided by dichotomies. The dichotomy is a reduction resource that dominates knowledge construction, but, nevertheless, constructs knowledge (a new, although necessarily, dichoto- 
mous knowledge). Prominence is given to this automatic resource of cognitive organization, applied to $\mathrm{KO}$, in the studies of Olson (e.g. 1997a; 2003) and (García Gutiérrez 2011c).

In this case, the idea is to place dichotomous reduction at the service of pluralism, namely, against itself. With the aim of creating a complex space in $\mathrm{KO}$ operations and tools, it is necessary to start from antonymous positions, namely, to establish two opposing concepts as poles of a dichotomous space. In a media information system, there can be thousands of examples, including the following:

$\begin{array}{ll}\begin{array}{ll}\text { Issue } \\ \text { Islamic veil }\end{array} & \begin{array}{l}\text { start position/end position } \\ \text { cultural right/cultural oppression }\end{array} \\ \text { abortion } & \text { women's right/infanticide } \\ \text { Zapatistas } & \text { national liberation/terrorism } \\ \text { consumption } & \text { freedom/alienation } \\ \text { Castrist regime } & \text { dictatorship/popular democracy } \\ \text { intervention in Iraq } & \text { solidarity/invasion } \\ \text { police intervention } & \text { forces of law and order/state violence } \\ \text { bombing } & \text { military operation/criminal action }\end{array}$

Between the polls of any one of the aforementioned dichotomies there is a $180^{\circ}$ angle (the inverted range symbolized by $\boldsymbol{\Lambda}$ ) which allows for an infinite number of positions on an issue that is located in the upper vertex. Between the two extremes of bars there are two polarized concepts, with the possibility of being exceeded by other more polarized ones, and, between them, all of the possible opinions are ordered in the same way as it would be done with the intermediate positions between yes/no, $1 / 0$, good/bad, beautiful/ugly, etc.

Digital systems enabled for $\mathrm{KO}$ operations ought to have algorithms that make it technically possible to implement the complex operator in order to democratically safeguard all positions in their processes and tools. The opinion of MKOS is one such position that must be democratically represented in consequence of the purposes of the complex operator, but then again it is not just another position since MKOS, as mediators, hold a privileged position. Moreover, they read, organize and represent not for themselves but for others. They are, therefore, symbolic consequences of their profession, with an unlimited and differed anonymous power to manipulate consciences in an uncontrollable process of, let us say, "doxological semiosis."

So as to correctly distinguish the range of the critical operator, namely, the tool-and objective of this paperthat MKOS should possess in order to explicitly express their opinion in the set of ethical-political operators which is indispensable for lending $\mathrm{KO}$ operations transparency and reliability, the transcultural operator will be outlined below.

\subsection{Transcultural operator $V$}

The transcultural operator is a category of collective organization and record retrieval based on agreement. Unlike the complex operator, it has the following characteristics:

- It stems from the consensus on an issue involving institutional interlocutors or known public and private ideological and cultural collectives, associated with the aim of ensuring that ethical, democratic and interculturally acceptable principles are upheld, transposing them to representations and metadata so as to guarantee dignity and freedom of expression, and that any possible manipulation or bias accompanying specific records remains clear-cut, respecting the presence of the said records on the Web, regardless of tendentiousness, bad faith or evident manipulation.

- Such a consensus is achieved by applying the dialogical ethics of Otto Apel (1985) in the context of a pragmatic development of the eristic dialectic of Schopenhauer (2002).

- Its application would be obligatory for MKOS working at institutions or media companies committed to an international association of transcultural ethics on the Web, which would have to be created for such a purpose ${ }^{1}$.

- The transcultural operator critically accompanies any record and, in the interests of freedom of expression, it cannot supplant it. It neither modifies nor eliminates the challenged metadata in a record, but complements them, when necessary, in three ways: 1) merging originally divergent positions through consensus; 2) favoring the dissemination and use of the record by means of the prestige of and confidence in a seal of approval supported and trans-ideologically and interculturally certified by mediators; 3 ) criticizing or altering the interest or dangerousness of a record in accordance with other internationally or interculturally adopted directives, such as human rights.

- The transcultural operator should only be used in cases of global importance in which there is a risk of grave or irreversible damage to the symbolic universe or democratic and human rights of citizens and, by extension, the right of cultures and civilizations to selfnarrative.

- The danger of this operator lies in the possibility of a convergence of interests so as to impose a dominant position, although such a position could be reported by the action of the complex operator-unfettered by norms or agreements-on ensuring that all opinions are voiced and, more importantly, by the critical operator on ensuring that the voice of the critical and self- 
critical kos is heard. The scenario of this potential debate would be in $\mathrm{KO}$ operations, tools and representations accommodating this particular "semiosis" of media memory so as not only to avoid the overlapping or erasing of collective transcultural labels, but also to ensure that they complement those used by mediators in general (by virtue of the complex operator) and, above all, by critical mediators. The relevant records would not be converted into palimpsests that silence previous opinions, but rather in authentic plural narratives of a collaborative and participative exomemory.

\subsection{Critical operator}

As has been seen, while transcultural operators focus on the consensus reached through an interlocution between positions on an issue, the aim of the complex operator is that of dissent.

Critical expression by MKOS in the processes and tools involved in $\mathrm{KO}$ could be regarded as a democratic right to freedom of expression, a political right covered by the complex operator. In fact, and as a development of this, the critical operator could be considered as a modality of the complex operator, although as a resource restricted to mediators, since the aim of the complex operator itself is to protect and channel the vision of all positions on an issue. As a result, the critical operator would be a space in the complex operator reserved for free expression (which could also be classified by rank) of MKOS who, in the information system, do not contribute with one more position-just as an author of a text does not-to the set of all the positions, but a privileged one and, therefore, simultaneously subject to greater influence and control. If the opinion of any position (except for the major voices and current affairs oracles, such as media corporations and groups) forms a part of a set, that of MKOS is transversal to that set and is, therefore, consubstantial with the risk of manipulation involved in mediation.

The critical operator is also a techno-ethical space destined to include the personal, ideological, cultural and social position of MKOS as mediators - their subjectivity, in short - in order to differentiate their legitimate biases from the results obtained through the use of $\mathrm{KO}$ forms and tools, regardless of their status and degree of application.

In their usual operations, MKOS work in a scenario supposedly lacking in subjectivity, their role being that of reproducing the author's biases and positions. However, such operations usually have a "cognitive" basis; that is, grounded on an automatism that reflects the "common sense" or good offices of KOS. In the face of reproduction, a simple fallacy of the system, it is necessary not only to vindicate the co-productive contribution of MKOS (in which they cooperate with the meaning intended by the author), but also their productive contribution (in which they operate independently from the author).

So as to establish the difference between obtaining objectified results by means of $\mathrm{KO}$ procedures and tools and the derivatives of subjectivity, the prior training of MKOS on two fronts is a must: 1) on that of criticism itself, in order to construct objections and observations on $\mathrm{KO}$ results (if possible, based on their independence, rather than on the editorial policy of a given media company, for which additional academic training in line with the critical objective would be necessary; and 2) on that of reflexivity; that is, the action of self-disclosure so as to able to distinguish between objective results and biases, between facts, datum and cultural or ideological interferences. As can be deduced from all this, reflexivity ought to contain a strong dose of self-criticism, since it is precisely its lack that determines how we identify personal and local interest with the collective and universal kind.

KO has Western roots, and the West (or Westerners) has always been convinced that its principles, procedures and technologies possess a universal value. It could be a legitimate self-acknowledgment - the right to defend a stance with all the arguments-but unforgiving with those who do not share that stance and are made to assume it through military, economic or propagandistic violence, or with minorities (or marginalized majorities) that do not even have the right to freedom of expression or to disseminate their own knowledge or collective exomemory on the Web. It is hardly surprising that our civilization has used armed force, not though for selfdefense, but rather to colonize the rest of the planet using these principles and technologies. And although it would be unfair to doubt the good faith of many Westerners that collaborate in this colossal project-MKOS, among others - what does indeed seem irrefutable is the absence of self-criticism and reflexivity in their operations.

The critical operator would transform all these functions of a cognitive nature in meta-cognitive operations; that is, non-automatic, conscious and reflexive, something that should be provided for in analysis forms and $\mathrm{KO}$ tools involved in the theoretically proposed procedure. Several telling situations that media $\mathrm{KO}$ is currently experiencing, and which should therefore be subject to an empirical and in-depth study, will be addressed below: in the case of written journalistic texts, the author's bias could be deliberately explicit, as in the so-called "opinion pieces" (editorials, critiques, analyses, columns, etc.). In this case, conventional MKOS would not have a hermeneutic option, since the conceptual meaning and expres- 
sion would be evident. Nevertheless, MKOS could, consciously or not, respect the author's vision or initiate a gradually disparate representation until gaining an antonymous enunciative position. Let us take a look at the example of an opinion piece entitled, "Zapatista terrorism attacks police." In this example, the keywords are used irrespective of whether or not they come from a system based on free or controlled language. The options for representation are as follows:

a) Representation by literal reproduction (incompatible with option b): EZLN (Zapatista Army of National Liberation) / terrorism / attack / police

b) Representation by free production of the MKO (incompatible with option a): EZLN / national liberation / self-defense / police attack

c) Representation in co-production by means of the critical operator (makes options a) and b) compatible in the metadata):

d) Representation of literal reproduction $=$ representation of co-production of the $\mathrm{MKO}$ as a supporter of the Zapatista movement: (EZLN / terrorism / attack / police $)+($ EZLN / national liberation / self-defense / police)

The simultaneous but formally differentiated presence of metadata, on one hand faithful to the author, and on the other hand radically critical with his/her position, prevents the concealment or hiding of each mode of enunciation of the conventional representations. In those, the author's opinions (merely reproduced) are mixed in the content metadata with the opinions of the MKO in an opaque and harmful way for the users and for the very transparency of the media exomemory. Even in those cases in which the position of the MKO supposes a necessary correction of an authorial position that is objectively judged fascist, totalitarian or openly contrary to human rights or dignity, the author's position would be equally protected by the right to freely express his/her opinion on the Web, and therefore must be clearly differentiated from the one expressed by the MKO.

In the case of those journalism genres based on supposedly objective data, such as news stories, reports and interviews, in other words, a typology in line with the standards taught in journalism textbooks with pretentions to objectivity-conventional MKOS would have a greater interpretative legitimization and conceptual margin, while critical MKOS would adopt an ethical position, maintaining the reproductive function, together with the coproductive one:
An example of a news story on corroborated facts: "Police charge against striking miners causes several deaths."

Options for representation:

a) Reproduction: police charge / miners / strike / deaths

b) Options for production:

- in favor of the police: police / use of force / miners / rebellion / casualties

- in favor of the miners: police / violence / miners / social demands / assassinations

c) Co-production:

reproduction index: police charge / miners / strike / deaths

co-production index:

- perspective 1: in favor of the police

- perspective 2: in favor of the miners

- perspective 3: against the police and miners

- perspective 4: in favor of the police and miners

- perspective 5: reproduction

- perspective 6: variants of options 1-4.

Another broad scenario that deserves a full program of research from this same approach, due to its exponential growth, is that of visual and audiovisual media production, above all documents with little or no text-in other words, those with insufficient or inexistent captions or voiceovers - except for audio clips - that transmit a decisive oral or written terminology. In such a case, $\mathrm{KO}$ operations would reach higher levels of interpretation given the inexhaustible polysemy of images, which for audiovisual MKOS would imply a challenge and a greater amount of daily responsibility, unprotected by reliable procedures stemming from the theory of KO. In any case, what have not been taken into account either are the editorial policies or style books of media companies, which impose analysis and representation criteria, limiting the possibilities of production and co-production by MKOS. However, MKOS with a critical training will always have a small amount of leeway by relying on the use of omissions, for instance, which would not be detected even by the most punctilious supervisor.

In addition to allowing for the critical voice of MKOS in $\mathrm{KO}$ processes and tools, applied to the media, the critical operator can have other uses. In the case of the thousands of errata or reductions of a cultural or metonymic nature, the space reserved for the interpretation or position of MKOS could be employed for avoiding mistakes that run the risk of being perpetuated or immediately universalized. It is not uncommon to see images in which the presenter or reporter mixes up the Ye'kwana with the 
Yanomami individuals or confuses Afghan soldiers for Pakistani ones or, as was customary in Hollywood films of the 1950s — although the identification persists in nonleisure spheres-Andalusian flamenco music with dance being performed in a $19^{\text {th }}$ century Mexican bar; without forgetting the habit of equating the Latin with the Hispanic or the Spanish. Metonymy is unhindered by cultural, geographic or chronological obstacles (especially relevant for collective memory) in its reductive progress.

\subsection{Conclusions and proposals}

From the aforementioned arguments, it is possible to arrive at the following conclusions and lines of actions:

- MKOS not only reproduce the information and opinion of the media authors (reporters, columnists, editors, etc.) in the metadata, but also produce their own bias and opinions. The metadata derived from the positions of the MKOS are mixed with those that represent more faithfully the positions of the authors, whose opinions are also reproduced by the MKO.

- The subjectivity of the opinions and biases of MKOS are transferred to $\mathrm{KO}$ operations (analysis and representation) and tools (classifications, thesauri, ontologies and any other structure of organization and management) applied to media discourse, regardless of the measures taken to prevent this.

- Such opinions and biases can and should be explicitly stated as an expression of a differentiated position, and even regarded as a right of MKOS as text co-producers.

- The restoring and adaptation of certain procedures of the reflexive sociology and applications of the critical hermeneutics to the MKOS' practices contribute to the transparency and reliability of their operations.

- KO operations and tools can and should open up spaces for freely circulating and complementing the opinions, positions and consensuses with regard to an issue, regulated by transcultural operators that ensure the dignity of memory, complex operators guaranteeing democracy and, as a modality of these, the critical operators proposed in this work, which explicitly involve kos as active co-producers.

- It is necessary to study the critical and self-critical training and the social responsibility of MKOS since the results of their operations have a decisive influence in the construction of reality by the media (media bios).

\section{Notes}

1. In line with the "prisoner's dilemma," widely studied from the perspective of the theory of imperfect rationality developed by Jon Elster (1979), the authors believe that the option of reaching a global agreement on certain labels and metadata would be a "maximinized" solution; i.e., the best solution among the worst available from the standpoint of practical rationality and, therefore, the media would be more likely to arrive at a consensus on certain sensitive issues.

\section{References}

Apel, Karl-Otto. 1985. La transformación de la filosofía. Madrid: Taurus.

Banos, E., Katakis, I., Bassiliades, N. and Tsoumakas, G. 2006. PersoNews: a personalized news reader enhanced by machine learning and semantic filtering. Lecture notes in computer science 4275: 975-82.

Beghtol, Clare. 2002. A proposed ethical warrant for global knowledge representation and organization systems. Journal of documentation 58: 507-32.

Beghtol, Clare. 2005. Ethical decision-making for knowledge representation and organization systems for global use. Journal of the American Society for Information Science and Technology 56: 903-12.

Berger, Peter L. and Luckmann, Thomas. 1995. Modernity, pluralism and the crisis of meaning: the orientation of modern man. Gütersloh: Bertelsmann Foundation Publishers.

Bouras, Christos and Tsogkas, Vassilis. 2010. Noun retrieval effect on text summarization and delivery of personalized news articles to the user's desktop. Data and knowledge engineering 69: 664-77.

Bordieu, Pierre. 2004. Science of science and reflexivity. Cambridge, UK: Polity.

Casillas, Arantza, González de Lena, Mayte and Martínez, Raquel. 2003. Partitional clustering experiments with news documents. In CICLing'03 proceedings of the 4 th international conference on computational linguistics and intelligent text processing. Berlin, Springer, pp. 615-8.

Chen, Hsin-Hsi and Lin, Chuan-Jie. 2000. A multilingual news summarizer. In COLING 00 proceedings of the 18th conference on computational linguistics - Volume 1. Stroudsburg, PA, Association for Computational Linguistics, pp. 159-65.

Eco, Umberto. 1993. Lector in fabula: la cooperación interpretativa en el texto narrativo. Barcelona: Lumen.

Elster, Jon. 1979. Ulysses and the sirens: studies in rationality and irrationality. Cambridge: Cambridge University Press.

Evans, David Kirk and Klavans, Judith L. 2003. A platform for multilingual news summarization. computer science technical report. New York: University of Columbia. Available http://www.cs.columbia.edu/techreports/ cucs-014-03.pdf.

Feinberg, Melanie. 2007. Hidden bias to responsible bias: An approach to information systems based on Hara- 
way's situated knowledges. Information Research 12. Available http://informationr.net/ir/12-4/colis07.html.

Feinberg. Melanie. 2011a. Expressive bibliography: personal collections in public space. Knowledge organization 38: 123-34.

Feinberg, Melanie. 2011b. Organization as expression: classification as digital media. In Winget, Megan A. and Aspray, William, eds., Digital media. Lanham, Md.: Scarecrow Press, pp. 115-33.

Fox, Melodie J. and Reece, Austin. 2013. The impossible decision: social tagging and Derrida's deconstructed hospitality. Knowledge organization 40: 260-5.

Frohmann, Bernd. 2008. Subjectivity and information ethics. Journal of the American Society for Information Science and Technology 59: 267-77.

García Gutiérrez, Antonio. 2002. Knowledge organization from a "culture of the border": towards a transcultural ethics of mediation. In Lopez-Huertas, María José, ed., Challenges in knowledge representations and organization for the 21st century: integration of knowledge across boundaries: proceedings of the seventh international ISKO conference (Granada, Spain, July 10-13, 2002). Advances in knowledge organization 8. Wurzburg: Ergon Verlag, pp. 516-22.

García Gutiérrez, Antonio. 2004. Otra memoria es posible. Estrategias descolonizadoras del archivo mundial. Buenos Aires: La Crujía.

García Gutiérrez, Antonio. 2007. Desclasificados: pluralismo lógico y violencia de la clasificación. Rubí, Barcelona: Anthropos.

García Gutiérrez, Antonio. 2011a. Epistemología de la documentación. Barcelona: Stonberg.

García Gutiérrez, Antonio. 2011b. Desclassification in knowledge organization: a post-epistemological essay. TransInformação 23: 5-14.

García Gutiérrez, Antonio. 2011c. Pensar en la transcultura. Mexico D.F.: Plaza y Valdés.

Giunchiglia, Fausto, Maltese, Vincenzo, Madalli, Devika, Baldry, Baldry, Anthony, Wallner, Cornelia, Lewis, Paul, Denecke, Kerstin, Skoutas, Dimitris and Marenzi, Ivana. 2009. Foundations for the representation of diversity, evolution, opinion and bias. Available http://eprints. biblio.unitn.it/1758/1/063.pdf.

Gouldner, Alvin. 1971. The coming crisis of western sociology. New York: Avon.

Guimarães, José Augusto Chaves and Fernández-Molina, Juan Carlos. 2002. Ethical aspects of knowledge organization and representation in the digital environment: Their articulation in professional codes of ethics. In López-Huertas, María José, ed., Challenges in knowledge representations and organization for the 21st century: integration of knowledge across boundaries: proceedings of the seventh international ISKO conference (Granada, Spain,
July 10-13, 2002). Advances in knowledge organization 8. Würzburg: Ergon Verlag, pp. 487-92.

Guimarães, José Augusto Chaves and Fernández-Molina, Juan Carlos. 2010. Ética en organización y representación del conocimiento: aspectos teóricos. Nuovi annali della Scuola Speciale per Archivisti e Bibliotecari 24: 235-51.

Habermas, Jürgen. 1971. Theory and practice. Boston: Beacon Press.

Hjørland, Birger. 2008. Deliberate bias in knowledge organization? In Arsenault, Clément and Tennis, Joseph T., eds., Cultural and identity in knowledge organization: proceedings of the tenth international ISKO conference. Advances in knowledge organization 11. Würzburg: Ergon Verlag, pp. 256-60.

Hjørland, Birger. 2013. User-based and cognitive approaches to knowledge organization. Knowledge organization 40: 11-27.

Hogan, Kristen. 2010. "Breaking secrets" in the catalog: proposing the black queer studies collection at the University of Texas at Austin. Progressive librarian 34-35: 50-7.

Huyssen, Andreas. 2000. Seduzidos pela memoria. Rio de Janeiro: Aeroplano; Universidade Candido Mendes; Museo de Arte Moderna.

Ibañez, Jesús. 1994. El regreso del sujeto: la investigación social de segundo orden. Madrid: Siglo XXI.

Latour, Bruno and Woolgar, Steve. 1979. Laboratory life: the social construction of scientific facts. Beverly Hills: Sage Publications.

Lyotard, Jean Francois. 1984. The postmodern condition: a report on knowledge. Minneapolis: University of Minnesota Press.

Madalli, Devika P. and Prasad, A.R.D. 2011. Analytico synthetic approach for handling knowledge diversity in media content analysis. In Slavic, Aida and Civallero, Edgardo, eds., Classification and ontology: formal approaches and access to knowledge: proceedings of the international UDC seminar, 19-20 September 2011, The Hague, The Netherlands. Würzburg: Ergon Verlag, pp. 229-39.

Mamakis, Georgios, Malamos, Athanasios G. and Ware, J.Andrew. 2011. An alternative approach for statistical single-label document classification of newspaper articles. Journal of information science 37: 293-303.

Martínez-Ávila, Daniel, Kipp, Margaret and Olson, Hope. 2012. DDC or BISAC: the changing balance between corporations and public institutions. Knowledge organization 39: 309-19.

Morin, Edgar. 1996. Introducción al pensamiento complejo. Barcelona: Gedisa.

Olson, Hope A. 1997a. The feminist and the emperor's new clothes: feminist deconstruction as a critical meth- 
odology for library and information studies. Library \& information science research 19: 181-98.

Olson, Hope A. 1997b. Thinking professionals: teaching critical cataloguing. Technical services quarterly 15: 51-66.

Olson, Hope A. 1998. Mapping beyond Dewey's boundaries: constructing classificatory space for marginalized knowledge domains. Library trends 47: 233-51.

Olson, Hope A. 2000. Difference, culture and change: the untapped potential of LCSH. Cataloging \& classification quarterly $29 \mathrm{n} 1 / 2$ : 53-71.

Olson, Hope A. 2001. Patriarchal structures of subject access and subversive techniques for change. Canadian journal for information and library science $26 \mathrm{n} 2 / 3: 1-29$.

Olson, Hope A. 2002a. The power to name: locating the limits of subject representation in libraries. Dordrecht: Kluwer.

Olson, Hope A. 2002b. Classification and universality: application and construction. Semiotica 139: 377-91.

Olson, Hope A. 2003. Transgressive deconstructions: feminist/postcolonial methodology for research in knowledge organization. In: Frías, José Antonio and Travieso, Críspulo eds., Tendencias de investigación en organización del conocimiento: Trends in knowledge organization research. Salamanca: Universidad de Salamanca, pp. 731-40.

Olson, Hope A. 2009. Introduction to the special issue on the ethics of information organization. Cataloging \& classification quarterly 47n.7: 609-11.

Rocha, Rocio and Cobo, Angel. 2011. Feature selection strategies for automated classification of digital media content. Journal of information science 37: 418-28.

Sarvabhotla, Kiran, Pingali, Prasad and Varma, Vasudeva. 2011. Sentiment classification: a lexical similarity based approach for extracting subjectivity in documents. Information retrieval 14: 337-53.

Sasaki, Michelli, Vogel, Michely Jabala Mamede and Kobashi, Nair Yumiko. 2012. Aspects of information or- ganization and retrieval from a news portal. In Neelameghan, A., and Raghavan, K.S., eds., Categories, Contexts and Relations in Knowledge Organization: Proceedings of the Twelfth International ISKO Conference 6-9 August 2012 Mysore, India. Würzburg, Germany: Ergon, pp. 206-11.

Segev, Elad. 2009. Google and the digital divide: the biases of online knowledge. Cambridge, Chandos.

Schopenhauer, Arthur. 2002. El arte de tener razón expuesto en 38 estratagemas. Madrid: Alianza.

Sodré, Muniz. 2002. Antropológica do espelho. Petrópolis, Rio de Janeiro: Vozes.

Tennis, Joseph T. 2012. A convenient verisimilitude or oppressive internalization? characterizing the ethical arguments surrounding hierarchical structures in knowledge organization systems. Knowledge organization 39: 394-97.

Tennis, Joseph T. 2013. Ethos and ideology of knowledge organization: toward precepts for an engaged. Knowledge organization 40: 42-9.

tierra, tatiana de la. 2007. Latina lesbian subject headings: the power of naming. In Roberto, K.R., ed., Radical cataloging: essays at the front. Jefferson, NC: McFarland \& Company, Inc., pp. 94-102.

Todorov, Tzvetan. 2000. Los abusos de la memoria. Barcelona: Paidós.

Whatmore, Geoffrey. 1978. The modern news library: documentation of current affairs in newspaper and broadcasting libraries. London: Library Association.

Wongchokprasitti, Chirayu and Brusilovsky, Peter. 2007. NewsMe: a case study for adaptive news systems with open user Model. In ICAS 07 proceedings of the third international conference on autonomic and autonomous systems. Washington, DC, IEEE Computer Society, pp. 69-74. 